\title{
A FORMAÇÃO DE PROFESSORES: O LETRAMENTO CRÍTICO NA SALA DE AULA E AS PRÁTICAS SOCIAIS
}

\section{A TEACHER EDUCATION: CRITIC LITERACY IN CLASSROOM THE PRACTICES AND SOCIAL}

\author{
Marcia Cristina Hoppe*
}

REsumo: Esse trabalho tem como objetivo refletir sobre: formação de professores, letramento crítico e práticas sociais. Pois, é através da busca de possíveis caminhos para a transformação das práticas de ensino-aprendizagem, e, que os mesmos possam apontar para diferentes formas de se desenvolver os cursos de formação docente, bem como relacioná-los ao letramento crítico em prol da formação de alunos mais críticos. A temática será formação de professores, letramento crítico e práticas sociais. Para as reflexões nos pautamos nos estudos de: Kleiman (1995); Rojo (2009); Street (1984,2003); Soares (2000): Costa-Hübes (2008). A metodologia adotada foi uma releitura e revisão bibliográfica. A pretensão, com o estudo foi o de contribuir para um ensino que forme cidadãos críticos.

Palavras-chave: Formação de professores; Letramento crítico; Práticas sociais.

AbstRact: This study aims to reflect on teacher education, critical literacy and social practices. It is through the search of possible ways for the transformation of teaching-learning practices that can suggest different forms of elaboration of teacher education courses, as well as relate them to critical literacy in favor of the education of critical students. The theme of the study is teacher education, critical literacy and social practices. The reflections were supported by the studies of Kleiman (1995), Rojo (2009), Street (1984.2003), Soares (2000): Costa Hübes (2008). The methodology adopted for the study is the literature review.It is expected that this study can contribute to teaching that forms critical citizens.

KEYwORDs: Teacher education; critical literacy, social practices.

\footnotetext{
"Mestre em Letras do Programa de Pós- graduação Stricto Sensu em Letras- área de Concentração em Linguagem e Sociedade, da Universidade Estadual do Oeste do Paraná- UNIOESTE.Sob a orientação da Profa. Dra. Terezinha da Conceição Costa - Hübes.Bolsista CAPES/INEP ( 2014) e pesquisadora no âmbito do Projeto OBEDUC.Desenvolvendo a pesquisa sobre Concepções de leitura dos professores : possíveis relações com resultados da Prova Brasil. Professora da Rede Municipal de Ensino de Cascavel- PR, atuando principalmente em turmas de alfabetização.. E-mail: inter_marcia@hotmail.com
} 


\section{INTRODUÇÃo}

Como o mundo da atuação e formação continuada de professores, ainda, nos parece em fase inicial, e que a escola deve ser um local para possíveis reflexões e a formação de sujeitos críticos, isso só será possível através das práticas sociais e de um letramento crítico. "Por isso, achamos que é através do ensino da língua, que o professor detém o conhecimento diferenciado, pois ele possui, em suas mãos, um critério" poderosíssimo, a língua e, ela quando ensinada, torna-se um instrumento para a prática social através do letramento crítico. Pois, a mesma propicia ao aluno encaminhamentos fundamentais, para a ampliação de horizontes e, se bem aplicados, para chegar-se ao conhecimento científico, promovendo assim a possibilidade de tornar-se um cidadão mais crítico.

Pensando na forma mais adequada para a organização do trabalho, o mesmo será dividido em quatro momentos de reflexões: inicialmente, a formação de professores de língua materna; na sequência o letramento crítico, posteriormente, o letramento e as práticas sociais e, por fim as considerações finais. A FORMAÇÃO DE PROFESSORES DE LÍNGUA
MATERNA

Iniciamos as nossas reflexões pensando no que seria a preparação do professor para o ensino mais contemporâneo. Para isso, nos pautamos nas palavras da autora Rojo (2009), quando afirma que: o ensino na escola deve contribuir para que o aluno "desenvolva certas competências básicas para o trato com as línguas, as linguagens, as mídias e as múltiplas práticas letradas, de maneira crítica, ética, democrática e protagonista" (ROJO, 2009, p. 119). Acordando com a autora, essa deveria ser também uma das metas da formação dos professores de língua materna.

Podemos verificar, então, de acordo com Costa-Hübes (2008), que a formação de professores ou continuada, seja, "como um ato continuum, como forma de educação permanente, pessoal e profissional, objetivando o desenvolvimento da profissão docente" (COSTA-HÜBES, 2008, p. 23). A autora ainda nos auxilia com suas contribuições quando afirma que:

Ao interpretar a formação de professores como um processo educativo permanente de (des)construção de conceitos e práticas, para corresponder às exigências do trabalho e da profissão, é possível afirmar que a formação continuada se insere, não como substituição, negação ou mesmo complementação da formação inicial, mas como um espaço de desenvolvimento ao longo da vida profissional, comportando objetivos, conteúdos, formas organizativas diferentes daquela, e que tem seu campo de atuação em outro contexto (COSTA-HÜBES, 2008, p. 23).

Todavia, podemos analisar ou interpretar a formação de professores como sendo algo positivo, já que a formação propicia um estudo para o desenvolvimento ao longo da vida profissional e não para algo pré- determinado. 
Mas, para entendermos realmente o que seja a formação de professores ou formação continuada, achamos relevante realizarmos a conceituação desses termos. Para tanto, nos pautamos em Fabre (1995), que retomando Pierre Goguelin (1987), no intuito de compreendermos melhor o que o referido termo nos pretende sinaliza:

pólo educar: provém do étimo latino educare (alimentar, criar...) e educere (fazer sair de...). Trata-se de um conceito abrangente que designa tanto o desenvolvimento intelectual ou moral como o físico; o pólo ensinar: com origem no latim insignare (conferir marca, uma distinção) aproxima-se dos vocábulos aprender, explicar, demonstrar e confere um sentido predominantemente operatório ou metodológico e institucional. "O ensino é uma educação intencional que se exerce numa instituição cujos fins são explícitos, os métodos codificados, e está assegurada por profissionais" (Fabre 1995, p. 22); o pólo instruir: do latim instruere (inserir, dispor...) apela aos conteúdos a transmitir, fornecendo ao espírito instrumentos intelectuais, informação esclarecedora; e por fim temos o pólo formar: tem origem no latim formare (dar o ser e a forma, organizar, estabelecer). O vocábulo apela a uma ação profunda e global da pessoa: transformação de todo $o$ ser configurando saberes, saber fazer e saber ser (apud SILVA, 2000, p. 94).

Analisando todos os conceitos percebemos que os mesmos dialogam uns com os outros, mas se diferenciam em algumas especificidades, o que precisamos levar em consideração. No entanto, refletimos e avaliamos que o que mais se aproxima do conceito que como formação de professores ou continuada é o pólo ("formar"), pois propõe uma mudança contínua do ser, uma constante "transformação de todo o ser" e implica etapas de desenvolvimento que precisam ser mediadas na escola.

Por isso, a formação de professores tem um papel de fundamental importância para a sociedade, pois se, por um lado, contribui para a evolução e o aperfeiçoamento do professor, por outro, contribui, com fundamental significado, para o sucesso escolar. Em com relação a isso, Formosinho (1991) aponta que:

O aperfeiçoamento dos professores tem finalidades individuais óbvias, mas também tem utilidade social. A formação contínua tem como finalidade última o aperfeiçoamento pessoal e social de cada professor, numa perspectiva de educação permanente. Mas tal aperfeiçoamento tem um efeito positivo no sistema escolar se se traduzir na melhoria da qualidade da educação oferecida às crianças. É este efeito positivo que explica as preocupações recentes do mundo ocidental com a formação contínua de professores (FORMOSINHO, 1991, p. 238).

Por fim, seja como forma de atualização de conhecimentos da formação inicial ou como processo educativo permanente, a formação de professores ou continuada precisa ser praticada com e, de forma reflexiva e que envolva o esforço coletivo de toda a equipe da educação (escolar): professores, funcionários, diretores e pais de alunos, no 
sentido de ser compreendida como fundamental para o desenvolvimento de uma educação mais crítica.

\section{O LETRAMENTO CRÍtICO}

Entendemos que a linguagem exerce um papel fundamental na formação crítica dos cidadãos. Isso porque, é por meio dela, que os discursos podem ser analisados e ter seus significados negociados e construídos socialmente. E que, ainda nos permite compreender que o letramento crítico pode ser provocado a partir do trabalho desenvolvido pelos professores, possibilitando assim, que os alunos cheguem às várias interpretações possíveis dos discursos produzidos nos textos (orais e/ou escritos) que são trabalhados em sala de aula.

Inicialmente além de pensarmos a prática docente através do letramento crítico, ainda é preciso, nos centralizar nos esforços educacionais na teoria e na prática dos professores, na realidade da sala de aula, pois é nela que estão os conceitos de verdade e as noções de mundo que o docente irá disseminar aos alunos. Azevedo (2010), afirma que o professor é o detentor do conhecimento e esse conhecimento interfere diretamente na constituição do outro, os alunos estão expostos aos conceitos de verdades e valores que serão trazidos em sala, pelo professor (AZEVEDO, 2010).

Portanto, o letramento crítico é um meio pelo qual passamos ou o aluno possa entender o contexto social, político e o ideológico em que está inserido. Ele está relacionado tanto com o poder, a diferença e a desigualdade.
No Brasil, ainda na atualidade, podemos perceber que o acesso à escolarização passa por uma hierarquia e é fragmentado, pois a cultura de quem detém o poder exerce as influências na vida da maioria dos seres humanos constantemente.

Para a autora Kleiman (1995), o fator letramento é tido como a chave para o sucesso dos indivíduos, a escola é tida como única porta para esse sucesso, ou seja, para ser "letrado" o único meio de acesso é pela escola, pois é nela onde o indivíduo adquirirá todo o conhecimento necessário para conseguir um lugar com condições básicas de ação social.

Para entendermos realmente o significado de letramento crítico, analisemos o que segue segundo Luke e Frebody (1997):

O letramento crítico leva em consideração uma série de princípios da educação que visam o desenvolvimento das práticas do discurso e de construção de sentidos. Inclui também uma consciência de como, para que e porque, e ainda para quem, e de quem é o interesse que os textos podem funcionar em particular. Ensiná-lo é encorajar o desenvolvimento das posições e práticas leitoras alternativas para que ocorram os questionamentos e as críticas as suas funções sociais. E, ainda mais, pressupõem o desenvolvimento de estratégias para que se possa falar sobre, reescrever e contestar os textos da vida cotidiana (LUKE E FREBODY, 1997, p.218).

Portanto, o letramento crítico deveria propiciar ao aluno o desenvolvimento de sua capacidade leitora ou proficiente, tor- 
nando-o um ser capacitado para, em todas as práticas sociais, saber criticar.

\section{LETRAMENTO E AS PRÁTICAS SOCIAIS}

A palavra letramento é um termo ainda razoavelmente novo e técnico. Surgiu em 1984, no livro "Literacy in theory and practice", quando Street( 2003), fez uso da expressão "Literacy practices", como sendo um meio para focalização das práticas sociais e a concepção do ler e escrever( STREET,2003, p.77). Portanto, letrado, passa a ser não mais só quem era versado nas letras ou em letras e literatura, mas sim, que além de dominar a leitura e a escrita, sabe fazer uso proficiente e frequente de ambas.

O letramento é um conceito com raízes na alfabetização e, por isso, com frequência ambos são confundidos.

Segundo Soares (2000), o termo letramento teria sido usado no Brasil pela primeira vez, por Mary Kato, em 1986, em seu livro" No mundo da escrita: uma perspectiva psicolinguística". Mas como parte de título de livro, aparece em 1995, no livro organizado por Angela Kleiman "Os significados do letramento" e "Alfabetização e letramento" de Leda V. Tfouni. Ou seja, como nos esclarece ainda, Soares (2000), o termo teria surgido a partir da tradução da palavra inglesa Literacy, tendo o seu significado:

...literacy é o estado ou condição que assume aquele que aprende a ler e escrever. Implícita nesse conceito está a ideia de que a escrita traz conseqüências sociais, culturais, políticas, econômicas, cognitivas, lingüísticas, quer para o grupo social em que seja introduzida, quer para o indivíduo que aprenda a usá-la (SOARES, 2000, p. 17).

Portanto, o letramento é uma prática que vai muito mais além da alfabetização, que está voltada para a leitura e a escrita e, não estando vinculada ao contexto social.

Uma diferença percebida sobre o letramento na educação brasileira, que não é mais suficiente o ler e o escrever, mas é necessário saber praticar a leitura em situações da realidade social, e ainda, o ato de ler faça sentido, colaborando no momento da prática da comunicação, tanto no meio escolar como fora dele.

Para a autora Kleiman (1995), a definição de letramento é o seguinte:

...o letramento significa uma prática discursiva de determinado grupo social, que está relacionada ao papel da escrita para tornar significativa essa interação oral, mas que não envolve, necessariamente, as atividades específicas de ler ou de escrever (KLEIMAN, 1995, p. 18).

Já, realizando uma reflexão sobre os significados de letramento, Tfouni (2010) nos sugere que não pode acontecer a redução do seu entendimento ao de alfabetização e ao ensino formal. É, portanto, como ela diz: "é um processo mais amplo que a alfabetização e que deve ser compreendido como um processo sócio-histórico". E, a autora ainda relaciona o letramento com o desenvolvimento das sociedades. Com relação a esse sentido, a autora explica que:

Em termos sociais mais amplos, o letramento é apontado como sendo 
produto do desenvolvimento do comércio, da diversificação dos meios de produção e da complexidade crescente da agricultura. Ao mesmo tempo, dentro de uma visão dialética, torna-se uma causa de transformações históricas profundas, como o aparecimento da máquina a vapor, da imprensa, do telescópio, e da sociedade industrial como um todo (TFOUNI, 2010, p. 23).

Portanto, o letramento estaria e seria causa e consequência do desenvolvimento ocorrido em todos os setores do meio social. Sendo assim, o seu significado (letramento) atribuído pela autora extrapolaria a escola e o processo de alfabetização, referindo-se a processos sociais mais amplos. "O letramento [...] focaliza os aspectos sócio-históricos da aquisição da escrita. [...] tem por objetivo investigar não somente quem é alfabetizado, mas também quem não é alfabetizado, e, nesse sentido, desliga-se de verificar o individual e centraliza-se no social mais amplo" (TFOUNI, 1988, apud MORTATTI, 2004, p. 89).

A autora Brotto (2008), nas suas reflexões, nos aponta as seguintes considerações a respeito da diversidade de práticas que a palavra letramento pode abranger. Em suas palavras:

Letramento é um termo recente que tem sido utilizado para conceituar e/ ou definir variados âmbitos de atuação e formas de participação dos sujeitos em práticas sociais relacionadas de algum modo à leitura e à escrita. Pode se referir a práticas de letramento de crianças em período anterior ao período de escolarização; à aprendizagem escolarizada da leitura e da escrita, inicial ou não; à participação de sujeitos analfabetos ou alfabetizados não escolarizados na cultura letrada, ou, ainda, referir-se à condição de participação de grupos sociais não alfabetizados ou com um nível precário de apropriação da escrita em práticas orais letradas (BROTTO, 2008, p. 11).

O que a autora deixa claro nesse recorte é o que Soares (2000), Kleiman (1995), Tfoni (2005) e Matencio (1994) também defendem: a posição de que o letramento está intimamente relacionado às práticas de uso da leitura e da escrita, ainda que em práticas orais. Assim, mesmo os adultos considerados analfabetos e as crianças que ainda não foram inseridas no processo de escolarização fazem parte de um meio letrado e, portanto, reconhecem a utilidade da leitura no seu cotidiano, identificando os motivos de seu uso.

Soares (2009), mesmo quando aponta a dificuldade de conseguir abranger toda a complexidade do significado do termo letramento em um único conceito, ela também expressa uma definição para o termo: Resultado da ação de ensinar e aprender as práticas sociais de leitura e escrita; o estado ou condição que adquire um grupo social ou um indivíduo como consequência de ter-se apropriado da escrita e de suas práticas sociais (SOARES, 2009, p. 39).

Assim, letramento estaria ligado aos usos e, também, às práticas de leitura e de escrita. Além disso, seria letrado o indivíduo ou grupo que desenvolve as habilidades não somente de ler e de escrever, mas sim que 
utilizaria a leitura e a escrita na sociedade, ou seja, para Soares, somente alfabetizar não garante a formação de sujeitos letrados. Para que o letramento aconteça, é necessário que esses sujeitos tenham oportunidades de vivenciar situações que envolvam a escrita e a leitura e que possam se inserir em um mundo letrado. "De acordo com Soares (2009) realidades de países como o nosso, o contato com livros, revistas e jornais não é, ainda, algo natural e acessível, portanto, a realidade de alguns contextos de nosso país não contribui para a formação de sujeitos letrados" (SOARES, 2009, p.58).

Para Kleiman (1995) o letramento não é algo restrito apenas para o sistema escolar, mas sim, cabe a ele principalmente, direcionar seus alunos para um processo ainda mais profundo nas práticas sociais que envolvem a leitura e a escrita. Portanto, saber ler e escrever diversas palavras, não é o suficiente capacitar os indivíduos. Surge então, a necessidade dele ser letrado e estar envolvido no processo de aprendizagem, e o educador deve estar capacitado e atualizado para responder às mudanças da sociedade, que se reflete em todos os setores, principalmente no setor da educação. Sabemos, ain$\mathrm{da}$, que alguns profissionais da educação se colocam em uma posição inatingível, cheios de suas certezas, e isso é um equívoco, pois o conhecimento nunca se completa, ou se finda, e o letramento é um exemplo disso.

Para findar nossas reflexões, destacamos que embora o meio escolar muitas vezes, ainda diminui certas práticas de letramento, pois já que ela é um dos veículos de maior importância para que o letramento seja propagado, tendo como um dos objetivos de maior importância possibilitar para que os alunos participem das várias práticas sociais que fazem a utilização da leitura e da escrita como agente de condução para uma vida com mais ética, crítica e principalmente democrática.

\section{Considerações FinaIs}

Podemos verificar através desta reflexão bibliográfica que os autores reforçam a necessidade e a importância da formação dos professores mais adequada, visto que, apesar de muitos dos professores possuírem curso superior, ainda existe um "despreparo" com relação a certas práticas pedagógicas que, muitas vezes, nos parece um tanto quanto estagnadas e moldadas dentro de projetos ou planejamentos.

O investimento em novas práticas na formação inicial de professores pode contribuir significativamente para que ocorram mudanças relevantes na escola. Assim, percebemos ainda, que os professores procuram (re) pensar seus cursos de formação e suas aulas para possibilitar, por meio da reflexão crítica sobre os modos atuais de usar a escrita e a leitura. E, que façam a incorporação efetiva das tecnologias no ensino/ aprendizagem e destacam a importância de discutir questões sobre as implicações sociais e culturais das novas práticas letradas.

Com relação ao letramento e as práticas sociais, a maioria dos autores acredita que letramento não é um método, e sim uma prática, que está inserida nas ações cotidianas da sociedade, havendo, a necessidade de uma mudança nas propostas 
pedagógicas em seja possível alfabetizar/ letrando, pois o processo de ensino aprendizagem da leitura e da escrita na escola, não pode ser visto como um mundo isolado e à parte e não ter a finalidade de preparar o aluno para a realidade na qual se insere.

É importante fazer destaque ainda, que, alguns autores consideram que o letramento inicia-se muito antes da alfabetização. Quando uma pessoa começa a interação social com as práticas sociais que fazem uso da leitura e da escrita, provando que não existe um nível zero de letramento, já que uma pessoa pode não ser alfabetizada, e ser letrada, trazendo consigo uma bagagem social de conhecimentos de mundo. Ou seja, o seu conhecimento do dia a dia, em que o mesmo convive, seu meio social.

Ainda, por mais limitada e arcaica que sejam as atividades desenvolvidas em sala de aula, a grande maioria dos alunos ainda consegue fazer uso da leitura e da escrita para poder interagir em diferentes contextos sociais, nas quais essas práticas são necessárias, validando a afirmação de Magda Soares: "o letramento abre caminhos para o indivíduo estabelecer conhecimentos do mundo em que vive". Kleiman (2005) e Soares (2008), afirmam que ações e atividades desenvolvidas em sala de aula, dentro de um contexto adequado, modificam o comportamento dos alunos, fazendo com que eles façam uso da leitura e da escrita, como prática social, facilitando sua inserção e participação na sociedade.

As informações contidas neste trabalho poderão dar suporte para aqueles educa- dores que tenham a intenção de rever suas propostas pedagógicas, quanto à formação de professores, às atividades de letramento ou até mesmo uma compreensão acerca de suas bases teóricas.

\section{REFERÊNCIAS}

AZEVEDO, A. S. Reconstruindo identidades discursivas de raça na sala de aula de língua estrangeira. 2010. 144. Dissertação (Mestrado em Linguística Aplicada) - Universidade Federal do Rio de Janeiro, Rio de Janeiro, 2010. BROTTO, I. J. O. Alfabetização: um tema, muitos sentidos. $238 \mathrm{f}$. Tese (Doutorado em Educação) - Programa de Pós Graduação em Educação, Universidade Federal do Paraná, Paraná, 2008.

COSTA-HÜBES, T. C. 0 processo de formação continuada dos professores no Oeste do Paraná: um resgate histórico-reflexivo da formação em Língua Portuguesa. Londrina, UEL, (Tese de Doutorado), 2008.

FABRE, M(1995). Penser la formation. Paris: PUF.

FORMOSINHO, J. Formação contínua de professores: Realidades e perspectivas. Aveiro: Universidade de Aveiro, 1991.

GOGUELIN, P. Formação continuada dos adultos. Martins: publicações América, 1987.

KLEIMAN, A. B. Os significados do letramento: uma nova perspectiva sobre a prática social da escrita. Campinas: Mercado de Letras, 1995.

LUKE, A., and FREEBODY, P. Shaping the social practices of reading. In: S. Muspratt., A. Luke and P. Freebody, eds. Constructing critical literacies: Teaching and learning textual practice, pp.185-225. Cresskill, NJ: Hampton Press, 1997. 
MATENCIO, M. de L. M. Leitura, produção de textos e a escola. Campinas, SP: Mercado da Letras, 1994.

ROJO, R, Letramentos múltiplos, escola e inclusão social. São Paulo: Parábola Editorial, 2009.

SOARES, M. Letramento e escolarização. In: Letramento no Brasil, reflexões a partir do INAF 2001 (org.) Vera Massagão Ribeiro - $2^{\mathrm{a}}$ Ed. - São Paulo, Global, 2004.

Alfabetização e Letramento. $5^{\mathrm{a}}$ ed., São Paulo: Contexto, 2008.

. Letramento: um tema em três

gêneros. $4^{\mathrm{a}} \mathrm{Ed}$., Belo Horizonte: Autêntica Editora, 2010.

STREET, B. Wat's new in the new literacies studies? Critical approaches to literacy in theory and practice. 2003 Current issues in Comparative Education, Teachers College, Columbia University, ALL RIGHTIS RESERVED Currents Issues in Comparative Education, Vol.5(2). Maio de 2003.

TFOUNI, L. V. Letramento e Alfabetização. $8^{a}$ Ed.- São Paulo, Cortez - (Coleção Questões da Nossa Época; v.47), 2006.

Recebido para publicação em 08 de maio. 2014. Aceito para publicação em 14 de maio 2015. 